\title{
Nasal responsiveness to allergen and histamine in patients with perennial rhinitis with and without a late phase response
}

\author{
C de Graaf-in't Veld, I M Garrelds, A W van Toorenenbergen, R Gerth van Wijk
}

\begin{abstract}
Background - In the lower airways an association has been found between early phase reaction (EPR), late phase reaction (LPR), and bronchial hyperreactivity. However, this association has not been shown for the upper airways in nasal pollen challenge studies. A study was undertaken to determine whether the EPR, LPR, and nasal hyperreactivity are related in perennial allergic rhinitis.
\end{abstract}

Methods - Twenty four patients with rhinitis who were allergic to house dust mite (HDM) were challenged with HDM extract. The nasal response was monitored by symptom scores and nasal lavages for up to 9.5 hours after challenge and concentrations of albumin, tryptase, and eosinophil cationic protein (ECP) in the lavage fluid were measured. Thirteen patients (defined as dual responders) had increased symptom scores between 3.5 and 9.5 hours compared with the baseline score. The other 11 patients (defined as early responders) showed an isolated EPR only. Nasal hyperreactivity was determined by nasal histamine challenge 24 hours later.

Results - Dual responders showed a significantly higher symptom score, albumin influx, and tryptase release during the EPR. During the late phase (3.5-9.5 hours) albumin influx was significantly increased at most time points and ECP release was significantly higher at 9.5 hours in the dual responder group. Dual responders showed a significantly stronger response to all doses of histamine. The area under the curve (AUC) of symptom scores during EPR and LPR and the AUC of the histamine dose response were significantly correlated (EPR-LPR: $r=0.49, p<0.01$; EPR-histamine: $r=0.75, p<0.001$; LPRhistamine: $r=0.66, p<0.001)$.

Conclusions - In patients with perennial allergic rhinitis the nasal responses to allergen and histamine are associated. Dual responders have an increased EPR, increased levels of mediators, and increased allergen-induced hyperreactivity.

(Thorax 1997;52:143-148)

Keywords: allergic rhinitis, house dust mite, nasal hyperreactivity, nasal provocation.

In atopic patients allergen challenge gives rise to increased responsiveness to allergen and non- specific stimuli. This phenomenon has been described for the upper as well as for the lower airways. ${ }^{1-4}$ In the lower airways the immediate response to allergen challenge is often followed by a late phase response. This bronchial late phase reaction is associated with increased inflammation and bronchial hyperreactivity. ${ }^{5-8}$ In the upper airways late phase responses have also been described. ${ }^{910}$ Several studies have been performed to find out whether similar associations could also be shown in patients with allergic rhinitis. However, no relation has been found between an increase in nasal hyperreactivity and late nasal response, ${ }^{11}$ between an increase in nasal hyperreactivity and activation of eosinophils, ${ }^{12}$ or between enhanced responsiveness to rechallenge with allergen and late nasal response. ${ }^{13}$ These studies were performed in pollen sensitive patients tested outside the pollen season.

In contrast, in a study with rhinitic patients allergic to house dust mite (HDM) we have shown an association between nasal responsiveness to allergen and pre-existing nasal hyperreactivity, ${ }^{14}$ a finding more in agreement with data from the lower airways. Like asthmatics, these patients also suffer from symptoms throughout the year. Due to this ongoing allergen exposure it might be expected that these patients become primed more and as a consequence develop an increased non-specific hyperreactivity. We therefore wanted to investigate further the relationship between nasal hyperreactivity and response to allergen challenge in this subgroup of patients with rhinitis.

Patients with perennial rhinitis were challenged first with HDM and 24 hours later with histamine and the clinical response, mediators, and nasal hyperreactivity of patients with and without a late nasal response were compared to investigate whether early phase nasal reaction (EPR), late phase nasal reaction (LPR), inflammation, and nasal hyperreactivity were associated in these patients.

\section{Methods}

SUBJECTS

Twenty four patients (13 men) of mean age 34 years (range 21-50) participated in the study. All were characterised by a history of perennial rhinitis and an intradermal skin reaction of at least one plus sign to $3 \mathrm{BU} / \mathrm{ml} \mathrm{HDM}$ extract (ALK Benelux, Groningen, The Netherlands) according to the standardised plus sign scoring system defined by Norman. ${ }^{15}$ Patients with pollen allergy were tested outside the pollen sea- 
son, and those with allergy to pets were only included if they had no contact with pets.

Symptomatic medication for rhinitis was withdrawn - oral corticosteroids two months before the start of the study, astemizole six weeks, nasal or inhaled corticosteroids, disodium cromoglycate and nedocromil sodium three weeks, and antihistamines three days before the start of the study. Patients with nasal polyposis and those who had undergone nasal surgery less than three months before the study or who had had a nasal infection during the two weeks before the study or immunotherapy in the past were excluded.

\section{STUDY DESIGN}

Patients were challenged with increasing doses of HDM extract. Symptom scores were recorded and nasal lavage fluid was obtained for up to 9.5 hours after HDM challenge. Allergeninduced nasal hyperreactivity was determined by nasal histamine provocation 24 hours later.

During the study patients were not allowed any medication that affected nasal function. The study was performed during the period from January to August; this period was chosen to minimise natural exposure to HDM.

All patients gave their written informed consent and the study was approved by the medical ethics committee of the University Hospital.

NASAL CHALLENGE WITH HDM AND HISTAMINE Challenges were performed in accordance with the methods described by Gerth van Wijk. ${ }^{114}$ Before starting the nasal challenges the patients waited for 30 minutes in order to give the nasal mucosa time to acclimatise. Each patient was challenged with three increasing doses of HDM extract (100, 1000 and $10000 \mathrm{BU} / \mathrm{ml}$; ALK Benelux, Groningen, The Netherlands) performed at 10 minute intervals after challenge with phosphate buffered saline (PBS) containing human serum albumin $0.03 \%$ and benzalkonium chloride $0.05 \%$ (ALK Benelux). The PBS and the different doses of HDM extract were sprayed into each nostril by means of a nasal pump spray delivering a fixed dose of $0.125 \mathrm{ml}$ solution. The nasal response was measured 10 minutes after each challenge, 30 minutes after the last challenge (HDM $10000 \mathrm{BU} / \mathrm{ml}$ ), and hourly for up to 9.5 hours after the last challenge. Nasal responsiveness was monitored by the number of sneezes, the amount of secretion collected according to Borum, ${ }^{16}$ and a symptom score according to Lebel et al. ${ }^{17}$

Nasal challenge with histamine phosphate $(0.25,0.50,1.0,2.0$ and $4 \mathrm{mg} / \mathrm{ml})$ was performed at five minute intervals after challenge with PBS. The amount of secretion, the number of sneezes, and the symptom score according to Lebel et $a l^{17}$ were used as nasal response indicators.

NASAL LAVAGE

Nasal lavages were performed as described by Naclerio et al. ${ }^{18}$ This protocol comprises four prechallenge lavages with isotonic saline solution to clear the nose from secretions and to obtain baseline levels of mediators. To prevent nasal congestion due to allergen challenge oxymetazoline $0.1 \%$ (two $0.125 \mathrm{ml}$ puffs) was applied in both nostrils. Five minutes later a nasal lavage was performed just before the nasal challenge with PBS. A nasal lavage was performed 10 minutes after PBS and after each allergen challenge, immediately before the subsequent challenge. Subsequently, lavage fluid was obtained hourly from 0.5 to 9.5 hours after the last allergen challenge. Nasal lavages were performed with $10 \mathrm{ml}$ isotonic saline solution $(0.9 \%)$ preheated to $37^{\circ} \mathrm{C}$. In each nostril $5 \mathrm{ml}$ saline was instilled with a pipette while the subject gently flexed his/her head backwards. After 10 seconds the lavage fluid was expelled and collected in tubes. This procedure has been shown to produce a mean (SD) recovery of 7.7 (1.2) $\mathrm{ml}^{14}$

\section{SYMPTOM SCORE}

Symptoms were recorded using a scoring system according to Lebel $e t a l^{17}$ at the time points of lavage. Symptom scores were graded in points as follows: $3-4$ sneezes $=1, \geq 5$ sneezes $=3$; anterior rhinorrhoea $=1$; posterior rhinorrhoea $=1$; difficult nasal breathing $=1$; one nostril blocked $=2$; both nostrils blocked $=3$; pruritus of the nose $=1$; pruritus of the palate or ear $=1$; and conjunctivitis $=$ 1 (total score $0-11$ ). In addition, the number of sneezes and the amount of secretion were noted.

Patients were divided into two groups according to their symptom scores: those with an early response only (defined as early responders) and those with both early and late phase symptoms (defined as dual responders). ${ }^{14}$ Patients whose symptom scores were above the baseline level at two consecutive time points that is, for at least one hour - between 3.5 and 9.5 hours were defined as dual responders. The others with symptom scores equal to or lower than the baseline score at 3.5-9.5 hours after challenge were assigned to the early responder group. The dual responder group included patients with either a dual response or prolonged/persistent response after challenge. The period from 3.5 to 9.5 hours after challenge was chosen because other investigators found a late phase nasal response in the same period.

\section{MEDIATOR ASSAYS}

Lavage fluid was stored on ice, centrifuged for 10 minutes at $400 \mathrm{~g}$, and the supernatant stored at $-20^{\circ} \mathrm{C}$. Histamine levels were measured with an automated fluorometric assay. ${ }^{19}$ Tryptase and eosinophil cationic protein (ECP) were determined by radioimmunoassay (RIA) according to the manufacturer's instructions (Pharmacia, Uppsala, Sweden), and albumin was determined by automatic kinetic nephelometry using an Array analyser (Beckmann, Mijdrecht, The Netherlands) according to the manufacturer's instructions. 

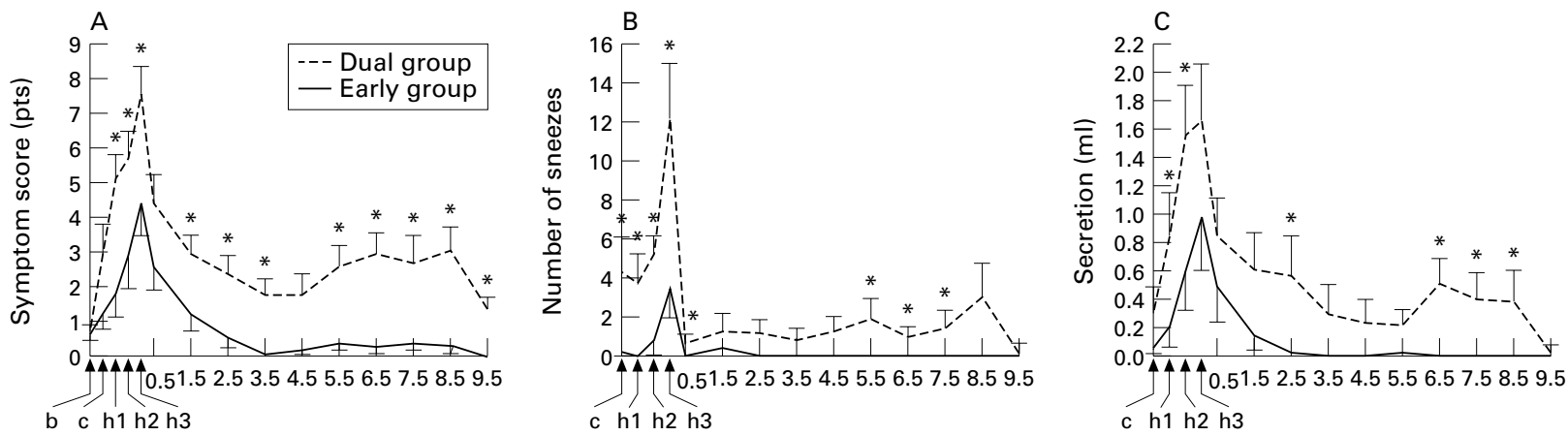

Hours after challenge

Figure 1 Clinical response to house dust mite (HDM) challenge by (A) symptom score, (B) number of sneezes, and (C) volume of secretions. The nasal response of dual and early responders was measured for up to 9.5 hours after HDM challenge. $b=$ before challenge, $c=10$ minutes after PBS, $h 1-h 3=10$ minutes after challenge with 100,1000 and $10000 \mathrm{BU} / \mathrm{ml} \mathrm{HDM}$ extract, respectively. ${ }^{*} p \leq 0.05$ (two sided test). Values are presented as mean (SE).

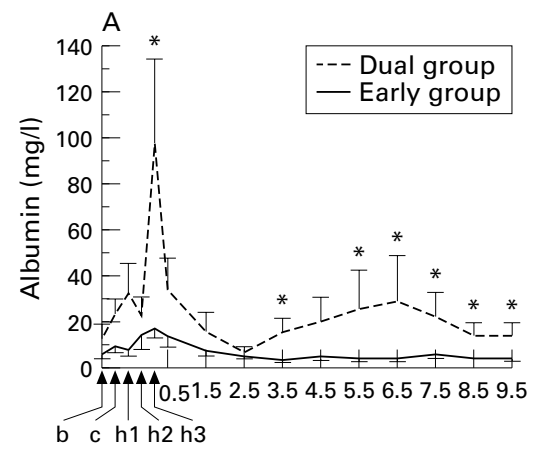

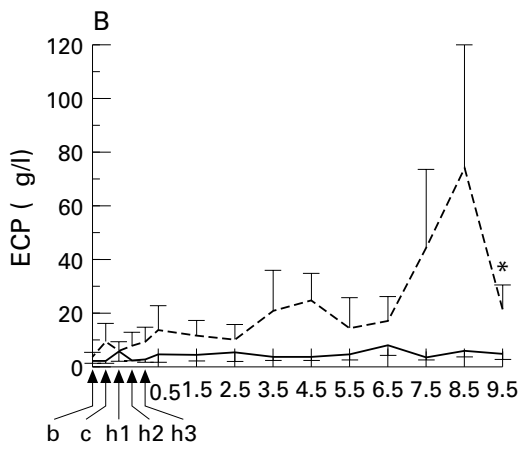

Hours after challenge

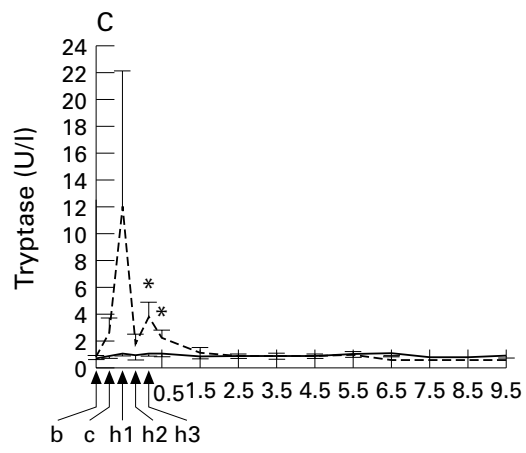

Figure 2 Mediators after house dust mite (HDM) challenge: (A) albumin, (B) ECP, (C) tryptase. Nasal response of dual and early responders was measured for up to 9.5 hours after HDM challenge. Abbreviations as in fig $1 .{ }^{*} p \leq 0.05$ (two sided test). Values are presented as mean (SE).
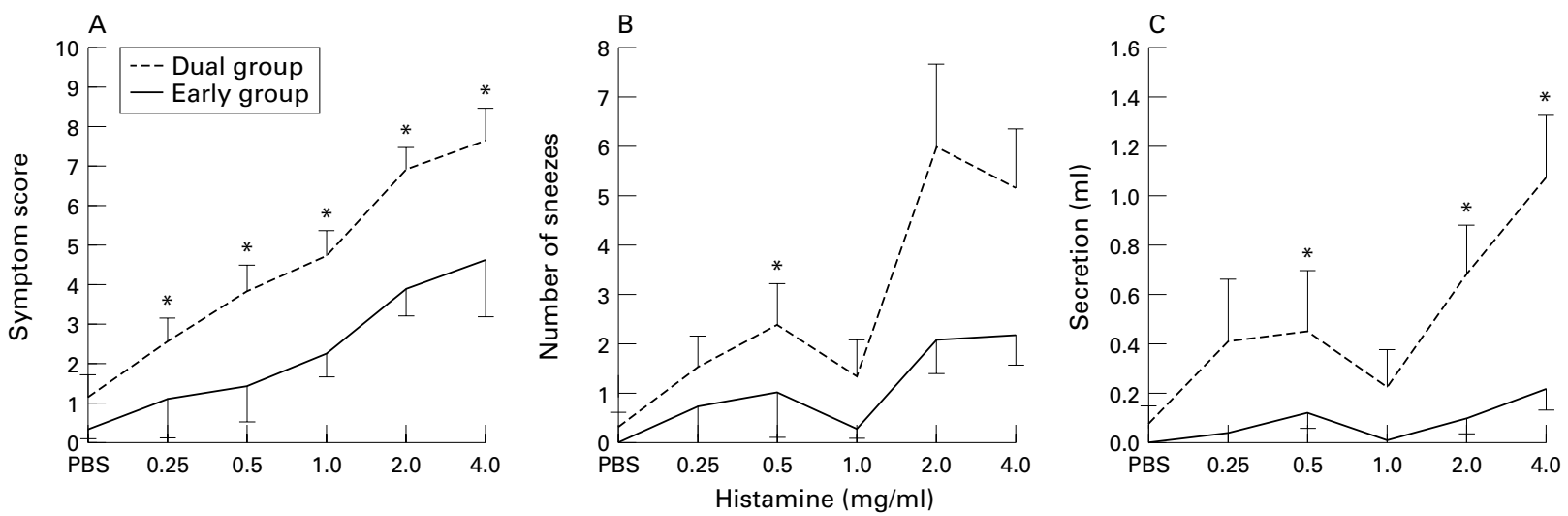

Figure 3 Responsiveness to histamine challenge measured by $(A)$ symptom score, (B) number of sneezes, and (C) volume of secretions in dual and early responders. ${ }^{*} p \leq 0.05$ (two sided test). Values are presented as mean (SE).

STATISTICAL ANALYSIS

Patients were divided into the early $(\mathrm{n}=11)$ or dual responder group $(n=13)$ according to their symptom scores. Differences between the groups in clinical response, mediators in lavage fluid, and histamine responsiveness were tested with the non-parametric Mann-Whitney U test. A two tailed $p$ value of $<0.05$ was considered significant.

Mediator release/influx during the EPR and LPR was tested by the Wilcoxon test. Since the mediators decreased after the EPR, often below the baseline levels, the individual peak levels during the LPR were compared with the lowest levels after the EPR to measure recurrence of mediator influx during the LPR. A two tailed $p$ value of $<0.05$ was considered significant.

The correlation between the area under the curve (AUC) of symptom scores during the EPR (HDM 100, 1000, $10000 \mathrm{BU} / \mathrm{ml}$ ) and LPR (3.5-9.5 hours) and the AUC of the histamine dose response was tested with the Spearman correlation test. 
Table 1 Profile of dual and early responders

\begin{tabular}{|c|c|c|c|}
\hline & Dual responders & Early responders & $p$ value \\
\hline $\begin{array}{l}\text { HDM }(10000 \mathrm{BU} / \mathrm{ml}) \\
\text { Symptom score (pts) } \\
\text { Albumin (mg/l) } \\
\text { Tryptase (U/1) }\end{array}$ & $\begin{array}{rr}7.7 & (0.7) \\
97.8 & (36.1) \\
4.0 & (0.9)\end{array}$ & $\begin{aligned} 4.4 & (0.9) \\
17.1 & (4.3) \\
1.0 & (0.2)\end{aligned}$ & $\begin{array}{l}0.006 \\
0.004 \\
0.002\end{array}$ \\
\hline $\begin{array}{l}3.5-9.5 \text { hours } \\
\text { AUC symptom score (pts) } \\
\text { AUC albumin }(\mathrm{mg} / \mathrm{l}) \\
\text { AUC ECP }(\mu \mathrm{g} / \mathrm{l})\end{array}$ & $\begin{array}{rr}16.2 & (2.5) \\
138.2(59.4) \\
216.1(116.2)\end{array}$ & $\begin{array}{r}1.6(0.8) \\
27.7(6.0) \\
34.3(12.8)\end{array}$ & $\begin{array}{l}0.0001 \\
0.01 \\
0.07\end{array}$ \\
\hline $\begin{array}{l}\text { Nasal hyperreactivity } \\
\text { AUC histamine dose response (pts) }\end{array}$ & $(2.5)$ & $13.0 \quad(3.2)$ & 0.002 \\
\hline
\end{tabular}

\section{Results}

Dual responders $(n=13)$ showed a significant immediate and late nasal response while early responders $(n=11)$ showed an immediate response only. The dual responder group consisted of 10 patients with a dual response and three patients with a prolonged response. The symptom scores and, to a lesser extent, the sneezing and secretory responses of the dual responder group were significantly higher at most time points than those of the early responder group (fig $1 \mathrm{~A}-\mathrm{C}$ ).

Both early and dual responders showed a significant influx of albumin following challenge with HDM $10000 \mathrm{BU} / \mathrm{ml}$ and during the LPR. Albumin influx in the dual responder group was significantly higher during both the early and late phase than in the early responder group (fig 2A). Patients in both groups showed a significant increase in ECP release during the LPR. ECP release during the late phase response was significantly higher at 9.5 hours and tended to be higher at 4.5 hours $(\mathrm{p}=0.06)$ in the dual responder group (fig $2 \mathrm{~B}$ ). During the EPR a significant release of tryptase was detected in the dual responders only. The high mean (SE) values at $100 \mathrm{BU} / \mathrm{ml} \mathrm{HDM}$ are largely due to one patient. Both groups showed a significant increase in tryptase release during the late phase period. Since the individual patients showed only short and small peak levels during the LPR, and as the individual peak levels were distributed at variable time points, these small individual tryptase peaks were levelled by presenting them as mean values as in fig 2C. Dual responders showed a significantly higher release of tryptase following challenge with HDM in a concentration of $10000 \mathrm{BU} / \mathrm{m}$ and at 0.5 hours (fig 2C).

Nasal responsiveness to histamine, as measured by the symptom score, was significantly higher in the dual responder group (fig 3A). Although graphically the baseline scores are different, statistically no significant difference was shown. When correcting for the baseline, dual responders still showed significantly increased symptom scores to all histamine doses. The number of sneezes of the dual responders was significantly higher at $0.5 \mathrm{mg} / \mathrm{ml}$ and tended to be higher at $0.25 \mathrm{mg} / \mathrm{ml}(\mathrm{p}=0.09)$ and $4.0 \mathrm{mg} / \mathrm{ml}$ ( $\mathrm{p}=0.07$; fig $3 \mathrm{~B})$. The secretory response tended to be stronger at $0.5 \mathrm{mg} / \mathrm{ml}$ $(p=0.07)$ and was significantly stronger at the two highest histamine doses (fig 3C).
The mean symptom scores and mediator release following challenge with HDM $10000 \mathrm{BU} / \mathrm{ml}$ and during 3.5-9.5 hours, and the mean nasal hyperreactivity (AUC of histamine dose response) are shown for both groups in table 1. Dual responders showed a significantly stronger response to HDM $10000 \mathrm{BU} / \mathrm{ml}$ during the LPR and to histamine. ECP during the LPR tended to be higher in the dual responders $(p=0.068)$.

The AUC of the symptom scores during EPR and LPR and the AUC of the histamine dose response curves were significantly correlated (EPR-LPR: $r=0.49, \mathrm{p}<0.01$; EPRhistamine: $r=0.75, \mathrm{p}<0.001$; LPR-histamine: $r=0.66, \mathrm{p}<0.001)$.

\section{Discussion}

A recent study of patients allergic to HDM revealed a relation between pre-existing nasal hyperreactivity and LPR.${ }^{14}$ In view of this finding, we wanted to investigate in more detail the relation between EPR, LPR, inflammation, and nasal hyperreactivity in patients allergic to HDM. Patients were challenged with high doses of HDM extract in order to obtain maximal nasal response. We did not challenge each patient with their individual threshold dose to induce a particular nasal response. Because we were interested in a spectrum of EPRs to investigate whether the intensity of the EPR is related to the presence of an LPR and increased hyperreactivity, each patient was challenged with the same doses of HDM to obtain a range of EPRs.

To define the late phase reaction in the nose is difficult. Mygind et al $l^{20}$ could not detect late phase reactions by means of symptom scores. In other studies in pollen sensitive patients late phase reactions have been determined by measurement of nasal obstruction and analysis of nasal lavage fluid. ${ }^{1021}$ We assigned patients to an early or dual responder group according to their symptom scores during the late phase period; this approach has been used in other studies. ${ }^{1422}$

A comparison of the clinical responses in the two groups showed that the immediate response was significantly higher in the dual responder group. In addition, the AUC of the symptom scores during the EPR and LPR were significantly correlated, which implies that a strong immediate response is necessary to induce a late phase response. Small et a ${ }^{23}$ recently found that the amounts of $\mathrm{LTC}_{4}$ and $\mathrm{PGD}_{2}$ during the EPR and LPR were correlated in a pollen challenge study, which also suggests a relation between the two phases. However, nasal symptoms during the EPR and LPR were not correlated.

Albumin, being the major protein in plasma, can be used as a marker of increased vasopermeability. ${ }^{2425}$ Albumin influx into nasal lavage fluid showed a pattern comparable with the symptom score: a dual response in the dual responder group and an immediate response only in the early responder group. However, individual early responders also had small albumin peak levels. Since these individual small 
peaks occurred at variable time points they were levelled by using the mean values as in fig 2 .

In order to study the inflammatory response we measured tryptase and ECP levels in lavage fluid. Tryptase, a specific marker for mast cell activation, ${ }^{26}$ has proved to be a useful marker of the immediate nasal reaction. ${ }^{27}$ The dual responders showed an increase in tryptase release compared with the early responders. During the LPR, however, both dual and early responders showed short small peaks of tryptase, suggesting some mast cell degranulation during this period. The same finding has been reported by Wang et al. ${ }^{28}$ The late phase response in the upper and lower airways is associated with influx of eosinophils. ${ }^{72}$ In both groups release of ECP, a marker for activated eosinophils, could be detected during the late phase period. ECP release from 3.5-9.5 hours (AUC) tended to be higher in the dual responder than in the early responder group, and was significantly higher 9.5 hours after allergen challenge.

Comparing allergen induced nasal hyperreactivity, dual responders showed a significantly higher clinical response at all histamine concentrations. The AUC of the symptom scores during EPR and LPR and the AUC of the histamine dose response curve were significantly correlated. This association between nasal hyperreactivity and LPR was not found in nasal pollen challenge studies (tested outside the pollen season). ${ }^{113031}$ The difference might be explained by patients allergic to HDM having more hyperreactive upper airways due to the continuous exposure to natural allergen.

The early and late phases might be influenced by the use of oxymetazoline. Svensson ${ }^{32}$ showed that oxymetazoline did not influence histamine induced plasma exudation but an effect on nasal patency appears probable. However, in spite of this bias we found a clearcut relationship between EPR, LPR, and nasal hyperreactivity. This systemic error, made in all patients, probably did not influence this association.

Dual and early responders showed the same response to allergen although the intensity of the clinical response and the amount of mediator release were increased in dual responders. It seems that the more intense the EPR, the more mediators and chemotactic factors are released. As a result, increased recruitment of inflammatory cells takes place, releasing increased amounts of mediators which, at a certain threshold level, are able to induce a recurrence of symptoms. The increased recruitment of inflammatory cells might also explain the increased nasal hyperreactivity to histamine in the dual responder group.

We conclude that, in patients with perennial allergic rhinitis, the EPR, LPR and hyperreactivity are significantly correlated just as in the lower airways. Patients with a clinical late phase response show an increased intensity of symptoms, mediator involvement, and nasal hyperreactivity.
This study was supported by Glaxo BV, Zeist, The Netherlands and by grant 92.74 of the Dutch Asthma Foundation, Leusden, The Netherlands.

1 Cockcroft DW, Ruffin RE, Dolovich J, Hargreave FE. Allergen-induced increase in non-allergic bronchial reactivity. Clin Allergy 1977;7:503-13.

2 Grønborg H, Borum P, Mygind N. Histamine and methacholine do not increase nasal reactivity. Clin Allergy 1986; 16:597-602.

3 Andersson M, Andersson P, Pipkorn U. Allergen-induced specific and non-specific nasal reactions. Acta Otolaryngol 1989;107:270-7.

4 Connell JT. Quantitative intranasal pollen challenge. II. Effect of daily pollen challenge, environmental pollen exposure, and placebo challenge on the nasal membrane. f Allergy 1968;41:123-39.

5 Cockroft DW. Mechanism of perennial allergic asthma Lancet 1983;ii:253-6.

6 Cartier A, Thomson NC, Frith PA, Roberts R, Tech M, Hargreave FE. Allergen-induced increase in bronchia responsiveness to histamine: relationship to the late asthmatic response and change in airway caliber. $\mathcal{F}$ Allergy Clin Immunol 1982;70:170-7.

7 Monchy de JGR, Kauffman HF, Venge P, Koëter GH, Jansen HM, Sluiter HJ, et al. Bronchoalveolar eosinophilia during allergen-induced late asthma reactions. Am Rev Respir Dis 1985;131:373-6.

8 Durham SR, Craddock CF, Cookson WO, Benson MK Increases in airway responsiveness to histamine precede allergen-induced late asthmatic responses. $\mathcal{F}$ Allergy Clin Immunol 1988;82:764-70.

9 Pelikan Z. Late and delayed responses of the nasal mucosa to allergen challenge. Ann Allergy 1978;41:37-46.

10 Ferguson H, Davies RI. Late-phase nasal reactions - reviewed and revisited. Respir Med 1991;85:247-9.

11 Gerth van Wijk R, Zijlstra FJ, van Toorenenbergen AW, Vermeulen A, Dieges PH. An isolated early response after nasal allergen challenge is sufficient to induce nasa hyperreactivity. Ann Allergy 1992;69:43-7.

12 Klementsson $H$, Andersson M, Baumgarten CR, Venge P Pipkorn U. Changes in non-specific nasal reactivity and eosinophil influx and activation after allergen challenge. Clin Exp Allergy 1990;20:539-49.

13 Iliopoulos O, Proud D, Adkinson NF, Creticos PS, Norman PS, Kagey-Sobotka A, et al. Effect of immunotherapy on the early, late and rechallenge nasal reaction to provocation with allergen-changes in inflammatory mediators and cells. w Allergy Clin Immunol 1991;87:855-66.

14 Gerth van Wijk R, van Toorenenbergen AW, Zijlstra FJ, Jansen APH, Dieges PH. Nasal hyperreactivity and its effects on early and late sequelae of nasal challenge with effects on early and late sequelae of nasal challenge with
house dust mite extract. Allergy Proc 1993;14:273-81.

15 Norman PS. Skin testing. In: Rose NR, Friedman H, eds. Manual of clinical immunology. 2nd edn. Washington: American Society for Microbiology, 1980: 789-93.

16 Borum P. Nasal methacholine challenge. F Allergy Clin Immunol 1979;63:253-7.

17 Lebel B, Bousquet J, Morel A, Chanal I, Godard P, Michel FB. Correlation between symptoms and the threshold for release of mediators in nasal secretions during nasa challenge with grass-pollen grains. F Allergy Clin Immunol 1988;82:869-77.

18 Naclerio RM, Meier HL, Kagey-Sobotka A, Adkinson NF $\mathrm{Jr}$, Meyers DA, Norman PS, et al. Mediator release after nasal airway challenge with allergen. Am Rev Respir Dis 1983;128:597-602.

19 Siraganian RP, Hook WA. Histamine release and assay methods for the study of human allergy. In: Rose NR, Friedman $\mathrm{H}$, eds. Manual of clinical immunology. 2nd edn. Washington: American Society of Microbiology, 1980: 808-21.

20 Mygind N, Grønborg H, Bisgaard H, Romeling F. Nasal late-phase response to allergen provocation: does it exist? In: Dijkman JH, van Herwaarden CLA, Hilvering $\mathrm{Chr}$ Kerrebijn KF, eds. New developments in mechanisms and treatment of bronchial obstruction. Astra Pharmaceuticals, 1988:41-50.

21 Naclerio RM, Proud D, Togias AG, Adkinson NF, Meyers DA, Kagey-Sobotka A, et al. Inflammatory mediators in late antigen-induced rhinitis. $N$ Engl f Med 1985;313 65-70.

22 Pastorello EA, Galeazzo Riario-Sforza G, Incorvaia C, Segala $M$, Fumagalli $M$, Gandini R. Comparison of rhinomanometry, symptom score, and inflammatory cell counts in assessing the nasal late-phase reaction to allergen challenge. F Allergy Clin Immunol 1994;93:85-92.

23 Small P, Biskin N, Barrett D. Effects of intensity of early response to allergen on the late phase of both the nose response to allergen on the late phas
and skin. Ann Allergy 1994;73:252-8.

24 Baumgarten CR, Togias AG, Naclerio RM, Lichtenstein LM, Norman PS, Proud D. Influx of kininogens into nasal $\mathrm{LM}$, Norman PS, Proud D. Influx of kininogens into nasal
secretions after antigen challenge of allergic individuals. $\mathcal{f}$ secretions after antigen chall
Clin Invest 1985;76:191-7.

25 Svensson C, Baumgarten CR, Pipkorn U, Alkner U, Persson CGA. Reversibility and reproducibility of histamine-induced plasma leakage in nasal airways. Thorax 1989;44 13-18.

26 Schwartz LB. Monoclonal antibodies against human mas cell tryptase demonstrate shared antigenic sites on subunits of tryptase and selective localisation of the enzyme to mast cells. F Immunol 1985;134:526-31.

27 Rasp G, Hochstrasser K. Tryptase in nasal fluid is a useful marker of allergic rhinitis. Allergy 1993;48:72-4. 
28 Wang D, Clement P, Smitz J, De Waele M, Derde MP. Correlations between complaints, inflammatory cells and mediator concentrations in nasal secretions in nasal challenge and during natural allergen exposure. Int Arch Allergy Immunol 1995;106:278-85.

29 Bascom R, Pipkorn U, Lichtenstein LM, Naclerio RM. The influx of inflammatory cells into nasal washings during the late response to allergen challenge. Am Rev Respir Dis 1988;138:406-12.

30 Andersson M, Kogerer BV, Andersson P, Pipkorn U. Aller- gen-induced nasal hyperreactivity appears unrelated to the size of the nasal and dermal immediate allergic reaction. Allergy 1987;42:631-7.

31 Small P, Biskin N, Barrett D. Relationships among ragweed skin tests and both allergen specific and nonspecific nasal provocation. Ann Allergy 1990;65:185-8.

32 Svensson C, Pipkorn U, Alkner U, Baumgarten CR, Persson CGA. Topical vasoconstrictor (oxymetazoline) does not affect histamine-induced mucosal exudation of plasma in human nasal airways. Clin Exp Allergy 1992;22:411-6. 